\title{
Fairness or Not? Health Resources Allocation in Chongqing-Based on Theil Index
}

\author{
Yu Wang1, Qing Tu1 ${ }^{1}$ Qin Lai², Li Huang ${ }^{*}$ \\ ${ }^{1}$ The School of Public Health and Management, Center for Medicine and Social Development, The Innovation \\ Center for Social Risk Governance in Health, Chongqing Medical University, Chongqing, China \\ ${ }^{2}$ Yongchuan Hospital Chongqing Medical University, Chongqing, China \\ ${ }^{3}$ The First Affiliated Hospital of Chongqing Medical University, Chongqing, China \\ Email: ${ }^{*}$ Ih2015@sina.com
}

Received 12 May 2015; accepted 7 July 2015; published 14 July 2015

\begin{abstract}
Object: To Provide a basis for the government optimizing the allocation of health resources. Methods: The overall fairness was analyzed by Theil index and Gini coefficient. The main causes of unfairness were estimated by the decomposability of Thiel index. Results: Health resources owned by the "One-hour Economic Circle" were 1.5 - 2 times than that of the "Two wings". Theil index and Gini coefficient of five health resources from small to large were sickbed, doctor, health worker, nurse, and medical equipment. Differences within region in the contribution rate of the total Theil index were greater than the difference between region and the tendency to expand. Conclusions: The total amount of the health resources in Chongqing is insufficient. The configuration of doctor is more equitable than nurse, while the medical equipment' fairness is worst. Differences within region mainly cause the unfairness.
\end{abstract}

\section{Keywords}

Health Resource, Theil Index, Fairness, Gine Coefficient

\section{Introduction}

Health services involve the most basic existence right. The focus of the medical and health system reform in China is to guarantee the social members to get a fair and effective health service [1]. Lorenz curve and Gini coefficient are used to evaluate the health resource allocation fairness in domestic [2]. Previous scholars use Gini coefficient to analyze health resource allocation fairness in Chongqing study. However, the Gini coefficient can only reflect the overall degree of unfair, and show the differences among the middle-income earners [3] [4]. Theil index is more sensitive for the bottom earners, and gives more focuses to vulnerable groups [2]. This paper combining Gini coefficient and Theil index to analyze comprehensively, and using the decomposability of Theil index detecting fairness deeply aims to find the main causes of unfairness in health resource allocation, evaluate "Corresponding author. 
health resource allocation fairness in Chongqing from 2009 to 2011, and provide scientific suggestions on optimizing the allocation of health resources for government.

\section{Materials and Methods}

\subsection{Materials}

Data sources come from Chongqing Health Statistics Yearbook (2009-2011), Chongqing Statistics Yearbook (2006-2012), and China Health Statistics Yearbook (2010-2012). This paper selects 7 key indictors through literature review and expert consultation, such as the number of bed in Chongqing health care institutions, health technicians, working traditional doctors and assistants, registered nurses, large medical equipment, population and land area.

\subsection{Methods}

\subsubsection{Lorenz Curve and Gini Coefficient}

In 1907, M. O. Lorenz, the U.S statistician, came up with famous Lorenz curve which shows inequality in resource allocation by its curvature frequency. Gini coefficient use the ratio between "unequal area" and "not equal area" which are from Lorenz curve to reflect distribution differences on income or equalization level of macroeconomic indicators [5].

The Gini Coefficient, a measure of distribution inequality, is defined as the ratio of the area between the line of equal distribution and the observed Lorenz Curve to the area under the uniform distribution, and has values within the range 0 (perfectly uniform distribution) to 1 (complete inequality). In an equivalent representation, the Gini Index is the Gini Coefficient expressed as a percentage, and is equal to the Gini Coefficient multiplied by $100[6][7]$.

\subsubsection{Theil Index}

In 1976, Theil, a Dutch economist, put forward Theil index, which detect unfairness and diversity according to the idea of Content and Entropy. The higher Theil index is, the unfairer resource allocation is. But this is a relative indicator, unlike Gini coefficient has a specific cordon [8].

Theil index has a characteristic of decomposability which can decompose area according to regional differences and inter-regional differences. The advantage is that Theil index can measure regional differences' and inter-regional differences' contribution to total variance, so as to find out the cause of changes in equity. Time series in Theil index can indicate dynamic change in regional differences and inter-regional differences [9].

\section{Results}

\subsection{Health Resource Allocation in Chongqing from 2009 to 2011}

Allocation of health resources in Chongqing is lower than the national average, and slightly lower than the average in the west. Allocation of health resources in Chongqing lags far behind Beijing, Shanghai, Tianjing, which are municipalities. For example, number of beds per thousand population, hygienic and technical personnel, number (assistant) medical practitioners, and registered nurses are less than half of Beijing and Shanghai (Table 1).

During 2009-2011, health resource allocation per thousand population is on rise year by year in Chongqing. Health resources in Chongqing mainly are concentrated in One-hour Economic Circle of the central city nine areas. Health resource allocation is the least in southeaster Chongqing. Health resources in One-hour Economic Circle are 1.5-2 times in two wings areas.

\subsection{Analyzing Fairness of Health Resource Allocation by Gini Coefficient}

According to population configuration, Gini coefficient of beds, health technicians, and doctors in Chongqing (2009-2011) is in the range of $0.15-0.3$, which means achievement the best state of fair. Gini coefficient of nurse is between $0.3-0.4$, which means fairness is better. Gini coefficient of large medical equipment is over 0.4, especially more than 0.5 in 2011, which means unfairness is up to the perilous state of the height (Table 2).

According to geographical configuration, the fairness of beds is the best among the others. During 2010 and 
Table 1. Key Indicators in four municipalities, West, Country from 2009 to 2011.

\begin{tabular}{|c|c|c|c|c|c|c|c|c|c|c|c|c|}
\hline \multirow{2}{*}{ Area } & \multicolumn{3}{|c|}{ Bed } & \multicolumn{3}{|c|}{ Health Technicians } & \multicolumn{3}{|c|}{$\begin{array}{l}\text { Number (Assistant) } \\
\text { Medical Practitioners }\end{array}$} & \multicolumn{3}{|c|}{ Registered Nurses } \\
\hline & 2009 & 2010 & 2011 & 2009 & 2010 & 2011 & 2009 & 2010 & 2011 & 2009 & 2010 & 2011 \\
\hline Country & 3.31 & 3.56 & 3.81 & 4.15 & 4.37 & 4.58 & 1.75 & 1.79 & 1.82 & 1.39 & 1.52 & 1.66 \\
\hline West & 3.10 & 3.35 & 3.62 & 3.59 & 3.76 & 4 & 1.56 & 1.56 & 1.6 & 1.14 & 1.26 & 1.4 \\
\hline Beijing & 7.23 & 7.38 & 7.41 & 12.88 & 13.6 & 14.21 & 5 & 5.24 & 5.44 & 4.94 & 5.35 & 5.7 \\
\hline Shanghai & 7.12 & 7.44 & 7.55 & 9.35 & 9.59 & 9.8 & 3.65 & 3.63 & 3.67 & 3.73 & 3.96 & 4.15 \\
\hline Tianjing & 4.71 & 4.96 & 4.96 & 6.86 & 7.11 & 7.36 & 2.77 & 2.89 & 2.99 & 2.34 & 2.46 & 2.59 \\
\hline Chongqing & 2.83 & 3.14 & 3.47 & 2.97 & 3.26 & 3.61 & 1.28 & 1.36 & 1.49 & 0.97 & 1.13 & 1.28 \\
\hline $\begin{array}{c}\text { One-Hour } \\
\text { Economic Circle }\end{array}$ & 3.53 & 3.77 & 4.09 & 3.73 & 4.06 & 4.43 & 1.57 & 1.66 & 1.79 & 1.28 & 1.47 & 1.66 \\
\hline $\begin{array}{l}\text { Northeastern } \\
\text { Chongqing }\end{array}$ & 1.99 & 2.36 & 2.67 & 2.06 & 2.31 & 2.64 & 0.95 & 1.01 & 1.16 & 0.6 & 0.73 & 0.83 \\
\hline $\begin{array}{l}\text { Southeaster } \\
\text { Chongqing }\end{array}$ & 1.8 & 2.22 & 2.72 & 1.8 & 2.05 & 2.3 & 0.82 & 0.85 & 0.92 & 0.5 & 0.61 & 0.75 \\
\hline
\end{tabular}

Table 2. Gini coefficient of health resource allocation in Chongqing from 2009 to 2011.

\begin{tabular}{|c|c|c|c|c|c|c|c|c|c|c|c|c|c|}
\hline \multirow{2}{*}{ Category } & \multirow{2}{*}{ Indicators } & \multicolumn{3}{|c|}{ Chongqing } & \multicolumn{3}{|c|}{ One-Hour Economic Circle } & \multicolumn{3}{|c|}{ Northeastern Chongqing } & \multicolumn{3}{|c|}{ Southeastern Chongqing } \\
\hline & & 2009 & 2010 & 2011 & 2009 & 2010 & 2011 & 2009 & 2010 & 2011 & 2009 & 2010 & 2011 \\
\hline \multirow{5}{*}{ Population } & Bed & 0.191 & 0.159 & 0.165 & 0.172 & 0.153 & 0.168 & 0.073 & 0.076 & 0.129 & 0.096 & 0.11 & 0.181 \\
\hline & $\begin{array}{c}\text { Health } \\
\text { Technicians }\end{array}$ & 0.246 & 0.25 & 0.238 & 0.229 & 0.254 & 0.25 & 0.141 & 0.126 & 0.146 & 0.126 & 0.17 & 0.177 \\
\hline & $\begin{array}{c}\text { Number } \\
\text { (Assistant) } \\
\text { Medical } \\
\text { Practitioner }\end{array}$ & 0.207 & 0.237 & 0.26 & 0.202 & 0.246 & 0.234 & 0.131 & 0.13 & 0.159 & 0.098 & 0.15 & 0.172 \\
\hline & $\begin{array}{l}\text { Registered } \\
\text { Nurse }\end{array}$ & 0.37 & 0.334 & 0.367 & 0.345 & 0.316 & 0.34 & 0.264 & 0.234 & 0.227 & 0.279 & 0.26 & 0.275 \\
\hline & $\begin{array}{c}\text { Large } \\
\text { Medical } \\
\text { Equipment }\end{array}$ & - & 0.45 & 0.608 & - & 0.435 & 0.446 & - & 0.264 & 0.305 & - & 0.53 & 0.43 \\
\hline \multirow{5}{*}{ Geography } & Bed & 0.412 & 0.376 & 0.371 & 0.224 & 0.192 & 0.228 & 0.282 & 0.285 & 0.346 & 0.101 & 0.12 & 0.207 \\
\hline & $\begin{array}{c}\text { Health } \\
\text { Technicians }\end{array}$ & 0.471 & 0.418 & 0.463 & 0.318 & 0.367 & 0.263 & 0.34 & 0.334 & 0.373 & 0.15 & 0.24 & 0.241 \\
\hline & $\begin{array}{c}\text { Number } \\
\text { (Assistant) } \\
\text { Medical } \\
\text { Practitioner }\end{array}$ & 0.429 & 0.413 & 0.449 & 0.289 & 0.339 & 0.25 & 0.326 & 0.328 & 0.39 & 0.09 & 0.17 & 0.214 \\
\hline & $\begin{array}{l}\text { Registered } \\
\text { Nurse }\end{array}$ & 0.576 & 0.476 & 0.539 & 0.454 & 0.432 & 0.324 & 0.453 & 0.441 & 0.439 & 0.288 & 0.31 & 0.335 \\
\hline & $\begin{array}{c}\text { Large } \\
\text { Medical } \\
\text { Equipment }\end{array}$ & - & 0.581 & 0.621 & - & 0.498 & 0.453 & - & 0.443 & 0.48 & - & 0.57 & 0.451 \\
\hline
\end{tabular}

2011, Gini coefficient of beds is less than 0.4, while the others are more than 0.4. Gini coefficient of nurses and large medical equipment are over 0.5 , which means unfairness is up to the perilous state of the height. The fairness of geographical configuration is worse than population configuration, which is related to traditional computing method.

In the view of different economic circle, whether according to population configuration or geographical con- 
figuration, the fairness of One-hour Economic Circle is the worst which is related to the excessive concentration of resources. According to population configuration, fairness in northeastern Chongqing is higher than in southeastern Chongqing. However, according to geographical configuration, the result is adverse.

\subsection{Analyzing Fairness of Health Resource Allocation by Theil Index}

\subsubsection{Theil Index}

During 2009-2011, Theil index of health resources allocation in "lap wings" is in the order as follows: One-hour economic circle, southeastern Chongqing, and northeast Chongqing. Theil index of one-hour economic circle is vary widely with two wings areas. It indicates that fairness of one-hour economic circle is the worst. Theil index is consistent with the Gini coefficient (Table 3).

\subsubsection{Decomposition of Theil Index}

In order to comprehend the contribution of inter-regional and regional differences to total Theil index and annual dynamic change, this study decomposes three indicators (bed, doctor and nurse) in Chongqing during 2006-2011 to time series analysis.

During 2006-2011, the difference of distribution of bed, doctor and nurse in inter-region is bigger than in region, which means that regional difference is the main cause of unfair in health resources allocation (Table 4). Inter-regional difference in three indicators contribution to total Theil index has a tendency to expansion. This indicates that unfairness in health resources allocation is becoming more and more obvious (Figure 1). During 2006-2011, regional difference contribution rate in bed increases apparently. Regional difference in doctor and nurse contribution rate stays $70 \%-80 \%$, which doesn't change within these six years.

Under the construction of "lap wings", regional difference in one-hour economic circle is more than two wings areas. Inter difference of doctor in one-hour economic circle has decreasing tendency, the others have increasing tendency (Figure 2).

Table 3. Theil index of health resources allocation from 2009 to 2011

\begin{tabular}{|c|c|c|c|c|c|c|c|c|c|c|c|c|}
\hline \multirow{2}{*}{ Indicators } & \multicolumn{3}{|c|}{ Chongqing } & \multicolumn{3}{|c|}{$\begin{array}{c}\text { One-Hour Economic } \\
\text { Circle }\end{array}$} & \multicolumn{3}{|c|}{ Northeast Chongqing } & \multicolumn{3}{|c|}{ Southeastern Chongqing } \\
\hline & 2009 & 2010 & 2011 & 2009 & 2010 & 2011 & 2009 & 2010 & 2011 & 2009 & 2010 & 2011 \\
\hline Bed & 0.049 & 0.042 & 0.043 & 0.047 & 0.044 & 0.046 & 0.010 & 0.009 & 0.013 & 0.011 & 0.022 & 0.024 \\
\hline Health Technicians & 0.070 & 0.067 & 0.064 & 0.070 & 0.070 & 0.069 & 0.024 & 0.021 & 0.019 & 0.024 & 0.026 & 0.022 \\
\hline $\begin{array}{l}\text { Number (Assistant) } \\
\text { Medical Practitioners }\end{array}$ & 0.057 & 0.061 & 0.077 & 0.062 & 0.066 & 0.063 & 0.018 & 0.017 & 0.020 & 0.014 & 0.025 & 0.021 \\
\hline Registered Nurses & 0.123 & 0.106 & 0.127 & 0.105 & 0.097 & 0.104 & 0.061 & 0.050 & 0.039 & 0.066 & 0.057 & 0.053 \\
\hline Large Medical Equipment & - & 0.190 & 0.350 & - & 0.180 & 0.187 & - & 0.061 & 0.067 & - & 0.232 & 0.137 \\
\hline
\end{tabular}

Table 4. Decomposition of theil index in bed, doctor and nurse from 2006 to 2011

\begin{tabular}{|c|c|c|c|c|c|c|c|c|c|}
\hline \multirow{2}{*}{ Year } & \multicolumn{3}{|c|}{ Bed } & \multicolumn{3}{|c|}{ Doctor } & \multicolumn{3}{|c|}{ Nurse } \\
\hline & Total Theil & Inter-Region & Region & Total Theil & Inter-Region & Region & Total Theil & Inter-Region & Region \\
\hline 2006 & 0.07 & 0.025 & 0.045 & 0.055 & 0.014 & 0.041 & 0.123 & 0.036 & 0.087 \\
\hline 2007 & 0.067 & 0.026 & 0.041 & 0.054 & 0.013 & 0.041 & 0.12 & 0.034 & 0.086 \\
\hline 2008 & 0.056 & 0.019 & 0.037 & 0.058 & 0.015 & 0.043 & 0.129 & 0.036 & 0.093 \\
\hline 2009 & 0.049 & 0.018 & 0.031 & 0.057 & 0.016 & 0.041 & 0.123 & 0.032 & 0.091 \\
\hline 2010 & 0.042 & 0.012 & 0.03 & 0.061 & 0.016 & 0.045 & 0.106 & 0.029 & 0.077 \\
\hline 2011 & 0.042 & 0.01 & 0.032 & 0.057 & 0.013 & 0.044 & 0.103 & 0.026 & 0.077 \\
\hline
\end{tabular}



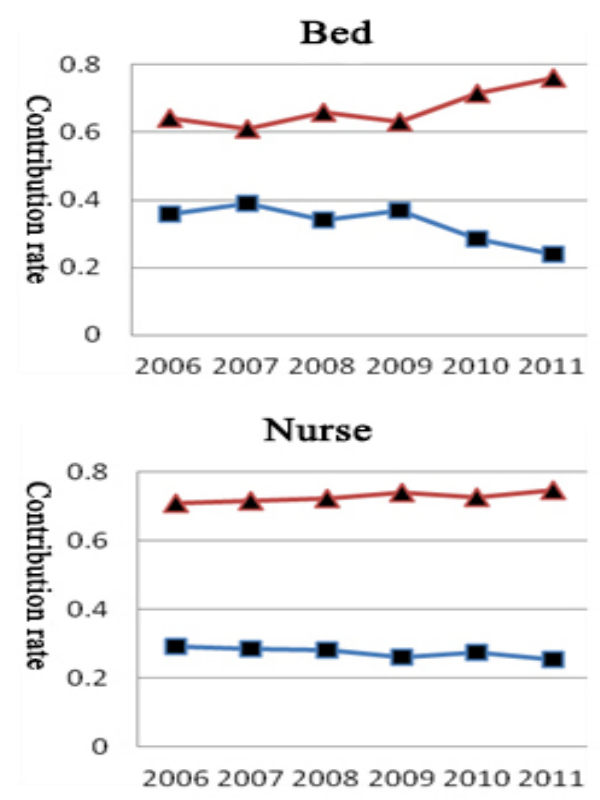
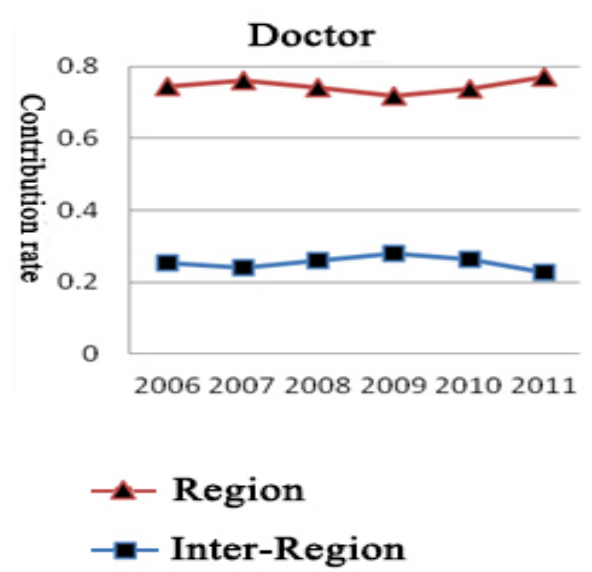

Figure 1. Inter-regional and regional difference of health resources Allocation contribution to Theil Index in Chongqing during 2006-2011.
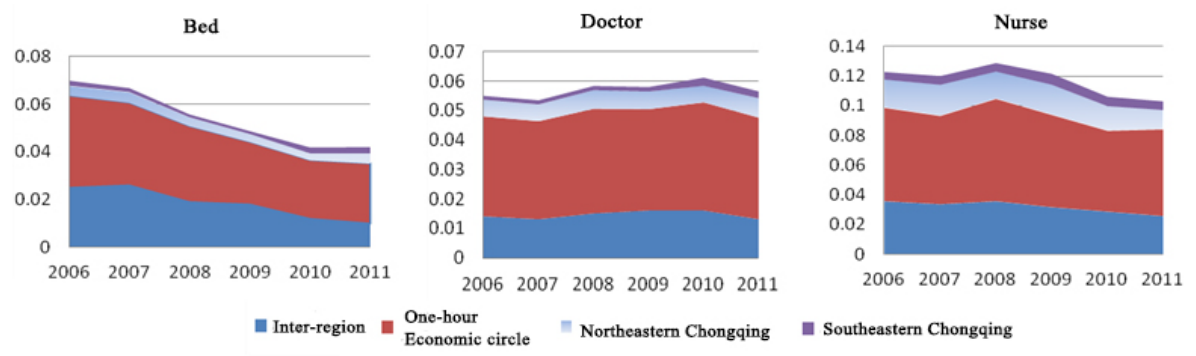

Figure 2. Decomposition of Theil Index in "lap wings" during 2006-2011.

\section{Conclusions}

\subsection{To Optimize Resources, Focusing on Demographic and Disease Spectrum Change}

This study indicates that because of weak infrastructure, health resources in Chongqing are extremely short. The number of health resources allocation in Chongqing needs increasing, inclining to "lap wings" areas, and shrinking the gap between rural and urban. On the one hand, government can increase health resources through introducing social capital and private capital to develop health service. On the other hand, health resources need to be optimized to improve allocation efficiencies and service qualities [10].

In terms of ways to allocate health resources, based on permanent residents including floating population, to allocate is the most scientific one [11]. In the sixth census, population aged 65 and over accounted for $11.56 \%$ of the total population. Ageing in Chongqing is the worst in China [12]. Population and disease spectrum change have to be considered when health resources are allocated by government to ensure fairness of health resources allocation in different ages. It is suggested to evaluate and predict disease spectrum and risk factors, and to enhance prevention of chronic and common diseases [13].

\subsection{To Adjust Structure of Human Resource and Improve Geographic Accessibility}

According to results, orders of fairness of health resources allocation in Chongqing are bed, doctor, health technician, nurse, and large medical equipment. What is more, fairness in population configuration is superior to geography configuration. Government should control rules to buy large medical equipment. Waste should be 
reduced through enhancing the relationship between hospital and community. Population in "two wings" areas is scattered. In the process of the allocation of health resources, geographical factors should be considered, and geographic accessibility of health services should be improved.

Health human resource is the main factor to impact health resources allocation [14]. According to WHO standard, the ratio of doctors and nurses is 1 to 2, but the ratio of doctors and nurses in Chongqing in 2011 is 1.16 to 1 , which is seriously imbalanced. In recent 2 years, government enhances the training of general practitioners. However, the quality and quantity of nursing staff have a big gap. Government should find a new way to explore new methods to educate health professionals, intensify construction of nurses in grassroots, and adjust the structure of medical staff.

\subsection{To promote Health Resources Flow in Different Economic Circle and Medical Institutions}

Health resources allocation in one-hour economic circle is $1.5-2$ times in "two wings" areas. Because geographic configuration is unequal, fairness is the worst. Chongqing has 19 public hospitals. Yuzhong district which covers $23.71 \mathrm{~m}^{2}$ has 11 public hospitals. Excessive concentration of resources is easy to bring the vicious competition among medical institutions and a serious waste of resources.

Government should promote health resources allocation flow between main urban and districts, and between large medical institutions and basic medical institutions. First, government should establish employment policy to attract graduates to basic medical institutions, such as loan policy and increasing training. Second, government should build reasonable mechanism of personnel flow. Third, government should establish long-term counterpart support mechanism. Personnel in large medical institutions need to guide community personal [15].

\subsection{To Establish Health Alliance and Integrate Advantage Resources}

According to this study, unfairness of health resources allocation in Chongqing is because of the difference in region and inter-region. Region difference in one-hour economic circle is more than in "two wings" areas. The main point to change the imbalance of health resources is to promote inter-regional health resources share and enhance construction of basic medical institutions.

Government should integrate advantage resources in one-hour economic circle, adjust different medical institutions on amount, layout and construction, and pay attention to open, just and fair environment. Through setting up health alliance, medical information can be shared, and special characteristics in different hospitals can be promoted. Two-way referral systems should be promoted by information share between community-based health service agencies and public hospitals to make advantageous resources into basic medical institutions.

\section{Acknowledgements}

The authors thank Chongqing Medical University for excellent assistance. The study was supported by Humanity and Social Science of Chongqing Education Committee (15SKG025), Chongqing Academy of Social Science, and Chongqing Science \& Technology Commission (2013YBGL138, 20130115, 2012-2-017). The authors also thank National Institute of Health (NIH) [(R01)RFA-WT-003].

\section{References}

[1] World Health Organization (2000) The World Health Report 2000: Health System. Improving Performance Printed in France, 144-150.

[2] Alvarez, A.A. (2007) Threshold Considerations in Fair Allocation of Health Resources: Justice beyond Scarcity. Bioethics, 21, 426-438. http://dx.doi.org/10.1111/j.1467-8519.2007.00580.x

[3] Zhang, Y.Q., Tang, G.L. and Wang, W.C. (2008) Study on Equity of Health Resources Distribution in Chongqing City. Chongqing Yixue, 37, 131-133.

[4] Feng, S.J., Xu, X.L. and Wen, C.G. (2012) Research on the Status and Equity of Health Resources Allocation of Chongqing. Modern Preventive Medicine, 39, 4433-4435.

[5] Pan American Health Organization (2001) Measuring Health Inequalities: Gini Coefficient and Concentration Index. Epidemiological Bulletin, 22, 3-4.

[6] Ishida, Y., Ohde, S., Takahashi, O., et al. (2012) Factors Affecting Health Care Utilization for Children in Japan. Pe- 
diatrics, 129, e113-e119. http://dx.doi.org/10.1542/peds.2011-1321

[7] Alvarez, J.L., Kunst, A.E., Leinsalu, M., et al. (2011) Educational Inequalities in Tuberculosis Mortality in Sixteen European Populations. The International Journal of Tuberculosis and Lung Disease, 15, 1461-1467. http://dx.doi.org/10.5588/ijtld.10.0252

[8] Cookson, R. and Dolan, P. (2000) Principles of Justice in Health Care Rationing. Journal of Medical Ethics, 26, 323329. http://dx.doi.org/10.1136/jme.26.5.323

[9] Eaves, D. (1998) An Examination of the Concept of Equity and the Implications for Health Policy If Equity Is Re-Asserted as One of the Key Government Objectives for the National Health Service. Journal of Nursing Management, 6, 215-221. http://dx.doi.org/10.1046/j.1365-2834.1998.00070.x

[10] Wagstaff, A. (2002) Inequality Aversion, Health Inequalities and Health Achievement. Health Economics, 21, 627-641. http://dx.doi.org/10.1016/S0167-6296(02)00006-1

[11] Li, Y.R. and Wei, Y. (2010) A Spatial-Temporal Analysis of Health Care and Mortality Inequalities in China. Eurasian Geography and Economics, 51, 767-787. http://dx.doi.org/10.2747/1539-7216.51.6.767

[12] Asante, A.D. and Zwi, AB. (2009) Factors Influencing Resource Allocation Decisions and Equity in the Health System of Ghana. Public Health, 123, 371-377. http://dx.doi.org/10.1016/j.puhe.2009.02.006

[13] Wang, F., Zhu, X.L. and Ding, X. (2012) Analyzing the Status of Grassroots Health Human Resources Allocation in China and Its Equity. The Chinese Health Service Management, 2, 108-110.

[14] Lei, G.H., Liu, R.M. and Chen, X.E. (2011) Constructing and Implementing the Performance Evaluation Management System of "Million Physician Supporting for the Rural Health Project". Chinese Health Economics, 9, 75-78.

[15] Dan, S.J. and Zhang, G.T. (2011) The Practice and Discussion of Medical Resources Integration in Shanghai Waigaoqiao District, Pudong New Area. Chinese Health Resources, 14, 325-326. 